\title{
Overview of Avicenna (Ibn Sina) Opinion on Stomach Swelling
}

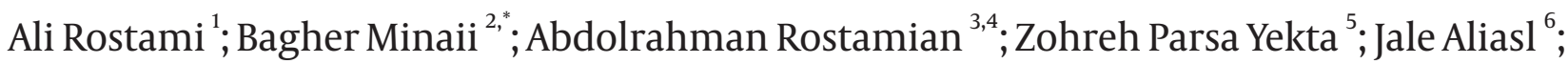 \\ Somaye Ahmadbegi ${ }^{2}$ \\ ${ }^{1}$ The Research Institute for Islamic and Complementary Medicine, Iran University of Medical Sciences, Tehran, IR Iran \\ 2 Depatment of Iranian Traditional Medicine, School of Traditional Medicine, Tehran University of Medical Sciences, Tehran, IR Iran \\ 3 Depatment of Rheumatology, Vali-asr Hospital, Imam Khomeini Hospital Center, Tehran University of Medical Sciences, Tehran, IR Iran \\ ${ }^{4}$ Center for Research on Occupational Diseases, Tehran University of Medical Sciences, Tehran, IR Iran \\ ${ }_{6}^{5}$ School of Nursing and Midwifery, Tehran University of Medical Sciences, Tehran, IR Iran \\ ${ }^{6}$ Traditional Medicine Clinical Trial Research Center, Shahed University, Tehran, IR Iran \\ ${ }^{*}$ Corresponding Author: Bagher Minaii, Depatment of Iranian Traditional Medicine, School of Traditional Medicine, Tehran University of Medical Sciences, Tehran, IR Iran. Tel: +98- \\ 2133972108,,E-mail: Minaezeb@sina.tums.ac.ir \\ Received: June 24, 2014; Revised: July 28, 2014; Accepted: August 27, 2014
}

Keywords: Stomach; Edema; Medicine, Traditional; Iran

\section{Dear Editor,}

The stomach is the most dilated portion of the GI tract (1). In Iranian traditional medicine (ITM) stomach is very important organ and its disorders can affect other organs (2-5). Avicenna (Ibn Sina), a Muslim scientist of the tenth and eleventh centuries has an important role in the history of medicine in Iran and the world (6). Canon, his famous book that was the greatest work by Avicenna, was translated into Latin in the 12th century and used as a major reference in medical education from the 12 th until the 17 th centuries (7). In addition, this book is one the most important textbooks in ITM. The foundation of ITM system was based on the balancing humors in the human body (8). In ITM, Mizaj (temperament) plays a key role in preventive, therapeutic, and lifestyle recommendations (9). Normally there are four humors in the human body: Phlegm or Balgham, Blood or Dam, Yellow bile or Safra, and Black bile or Sauda (10). Their imbalances in the body causes some disorders such as stomach swelling $(2,8)$. Persistent or repeated stomach pain that does not resolve with suitable treatments is the main symptom of stomach swelling (8). According to Avicenna, swelling is a complex disease (8). Swelling is thickness and bulging occurring in organ by material accumulation that expand it and fills the cavity. This material is usually infused by another organ or the organ of swelling itself $(2,8)$. Stomach swelling is divided into different types according to the materials: "warm" (Haar Safravi or Damavi), "cold Phlegm" (Barede Balghami), and "Solbe Ghaliz" (Hard and thick swelling) (8). The warm swelling is made by not only blood or yellow bile, but also any substance that is warm in essence or is heated by infection $(2,8)$. Prolonged and progressive pain, severe inflammation, strong burned, thirst and as- sociated fever, and radiating pain are the symptoms of warm swelling. It may even lead to a mixing of mind, melancholy, and meningitis (8). "Cold phlegm" swelling is made by phlegm and predisposing factors such as moisture, indigestion, exercise reduction, and other moisture-generating causes. The symptoms and signs of "cold Phlegm" swelling are persistent or repeated pain even during sleep, diluted and increased mouth water, leaden face color, little thirst, poor digestion, poor appetite, hate and suffer moist food, tendency to dry food, without fever, inflammation, and obsession (8). Sometimes, hard and thick swelling in the stomach is formed primarily by "Sauda" or from transmission and conversion of warm swellings. Phlegm swelling seldom becomes the hard stomach swelling. There are strength to the touch, a lot of dryness, loss of body weight, and other symptoms associated with swelling in the stomach $(2,8)$. Treatment in warm swelling includes reducing the swelling matter by venesection or prescribed laxatives, reducing the swelling by rubbing astringent and cold medications over swollen stomach, and avoiding vomiting and potent laxatives. Topical use of Radea (deterrent) drugs, Quince oil, and grated cucurbit, avoiding food, and use of easily digestible food at first and then laxative food and drugs such as beer, cucurbit, and Khiarshanbar (Cassia fistula) is recommended. Safravi swelling remedy is consisted of topical cold drugs such as Sandal (Santalum album), Kafoor (Cinnamomum camphora), alcohol-free beer, and Enabolsalab (Solanum nigrum L.). Treatment in "cold Phlegm" swelling include oral use of astringent solvent drugs such as extract of Celery and Fennel, almond oil, topical use of Baboone (Matricaria chamomilla) and shebet (Anethum graveolens), and avoiding vomiting. Finally, potent solvent drugs is recommended in hard swelling

Copyright ( ) 2014, Iranian Red Crescent Medical Journal; Published by Kowsar. This is an open-access article distributed under the terms of the Creative Commons Attribution-NonCommercial 4.0 International License (http://creativecommons.org/licenses/by-nc/4.0/) which permits copy and redistribute the material just in noncommercial usages, provided the original work is properly cited. 
astringent and use of camel bone marrow and cow calf brain in topical drugs is obligatory $(2,8)$. Based on this study, diagnosis and treatments of stomach swelling can be helpful in patients with persistent or repeated episodes stomachache.

\section{References}

1. Cheng LK, O'Grady G, Du P, Egbuji JU, Windsor JA, Pullan AJ. Gastrointestinal system. Wiley Interdiscip Rev Syst Biol Med. 2010;2(1):65-79.

2. Motavasselian M, Tavakkoli Kakhki M, Shams Ardekani MR. Indigestion Leads to Depression: Avicenna's Point of View. Iran Red Crescent Med J. 2014;16(2):15959.

3. Shirzad M, Mosaddegh M, Minaii B, Nikbakht Nasrabadi A, Ahmadian-Attari MM. The relationship between heart and stomach in Iranian traditional medicine: a new concept in cardiovascular disease management. Int J Cardiol. 2013;165(3):556-7.

4. Fazljou SM, Togha M, Ghabili K, Alizadeh M, Keshavarz M. In commemorating one thousandth anniversary of the Avicenna's Can- on of Medicine: gastric headache, a forgotten clinical entity from the medieval Persia. Acta Med Iran. 2013;51(5):279-83.

5. Azam Khan M. Aksir Azam (Persian).Tehran: The Institute for Medical History-Islamic and Complementary Medicine, Tehran University of Medical Sciences; 2004

6. Moosavi J. The place of avicenna in the history of medicine. Avicenna J Med Biotechnol. 2009;1(1):3-8.

7. Saffari M, Pakpour AH. Avicenna's Canon of Medicine: a look at health, public health, and environmental sanitation. Arch Iran Med. 2012;15(12):785-9.

8. Avicenna M. Al Qanun Fi Al-Tibb(Arabic).Beirut: Alaalami Library; 2005.

9. Mojahedi M, Naseri M, Majdzadeh R, Keshavarz M, Ebadini M, Nazem E, et al. Reliability and Validity Assessment of Mizaj Questionnaire: A Novel Self-report Scale in Iranian Traditional Medicine. Iran Red Crescent Med J. 2014;16(3):15924.

10. Emtiazy M, Keshavarz M, Khodadoost M, Kamalinejad M, Gooshahgir SA, Shahrad Bajestani H, et al. Relation between Body Humors and Hypercholesterolemia: An Iranian Traditional Medicine Perspective Based on the Teaching of Avicenna. Iran Red Crescent Med J. 2012;14(3):133-8. 